\title{
Rectal Cancer With Metastasis to the Face
}

\author{
Doğan YAZILITAS ${ }^{1}$, Mutlu DOGAN ${ }^{1}$, Ayse B. ILERI ${ }^{2}$, Nuriye OZDEMIR ${ }^{1}$, \\ Nebi S. DEMIRCI ${ }^{1}$, Nurullah ZENGIN ${ }^{1}$
}

\author{
${ }^{1}$ Ankara Numune Training and Reserch School, Department of Medical Oncology \\ ${ }^{2}$ Ankara Numune Training and Reserch School, Department of Medical Pathology, Ankara, TURKEY
}

\section{Dear Editor,}

Colorectal cancer is the third leading cancer all around the world following lung and prostate cancers. ${ }^{1}$ Rectal cancer (RC) metastasis mainly occurs in the regional lymph nodes. Liver is the most common site for hematogenous metastasis. Lung, bone and brain are other metastatic sites, however distant skin metastasis is rare in RC. ${ }^{2}$ Skin metastasis in RC might occur in locoregional area. ${ }^{2,3}$ In here, a 50-year old RC female with forehead metastasis is presented with review of the literature.

A 50-year old female admitted to the hospital 2 years ago with a history of intermittant hematochezia for 3 months. She was diagnosed rectal cancer with a solid liver metastasis (33x32 mm). Liver metastasectomy with primary surgery for RC was performed after 3 cycles of chemotherapy (mFOLFOX6). She had also postoperatively 2 cycles of mFOLFOX6 with locoregional chemoradiotherapy (5-FU $200 \mathrm{mg} / \mathrm{m}^{2} /$ day continuous infusion with radiotherapy). However, she had multiple liver metastasis after 11 months of follow-up. K-ras mutation analysis was positive for codon 12 Gly12Asp (G12D). She had progression in multiple liver metastasis with FOLFIRI-Bevacizumab. There was an isolated hyperemic fragile lesion with a diameter of $1 \times 1 \mathrm{~cm}$ in the forehead without any other skin lesions after 7 months of follow-up with multiple liver metastasis (Figure 1). The exisional biopsy of this lesion revealed rectal adenocarcinoma metastasis (Figure 2). So, she was again given pal- liative chemotherapy for multiple liver metastasis (CAPOX regimen )

Visceral metastasis (i.e. liver, lung) occurs by hematogenous metastasis whereas regional nodal metastasis occurs by lymphatic metastasis in colorectal cancer. Liver is the most common site for metastasis. Increased motility and invasiveness of the tumor cells contribute to the damage of basal membrane leading to tumor embolism. Tumor embolism contributes to the occlusion of capillaries and extravasation of the tumor cells in hematogenous metastasis. Skin metastasis occurs by hematogenous metastasis or locoregional seeding during operation. ${ }^{4}$

The cancer patients with skin lesions on face should be evaluated for skin metastasis or paraneoplastic syndromes besides cutaneous malignancies, such as basal cell carcinoma or squamous cell carcinoma, paraneoplastic skin lesions or metastasis. Zona zoster should be also ruled out, especially in those with pain related to the locoregional involvements . Cutaneous metastasis on face in colorectal carcinoma is rare as mentioned above. Detailed dermatological and systemic physical examination should be performed for the patient for additional lesions. An isolated skin lesion gives rise to other causes rather than isolated metastasis, especially in those that has low incidence of skin metastasis like colorectal cancer. 


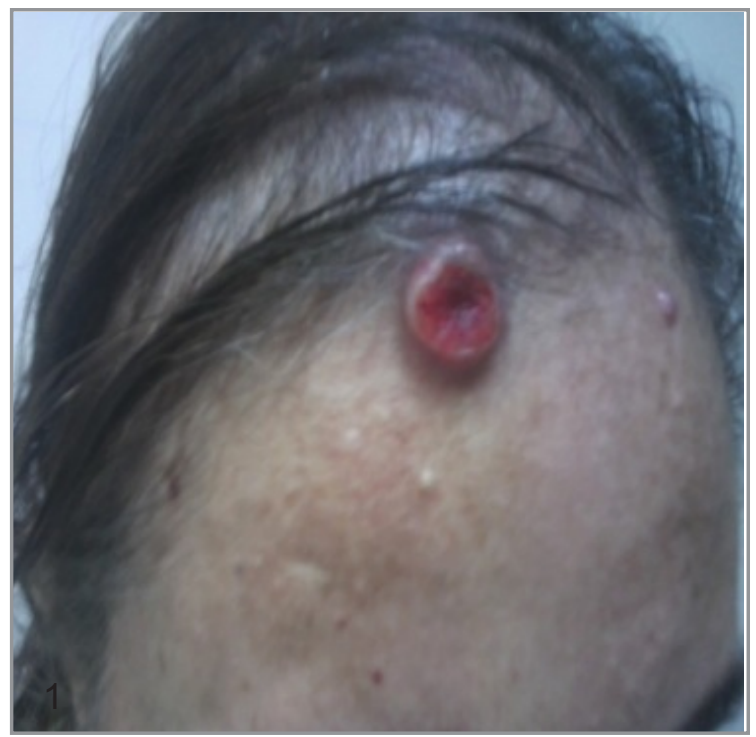

Figure 1. An ulcerated fragile skin metastasis on the forehead

Skin metastasis is reported as $5.3 \%$ and is more common in breast cancer with a predominance of thoracal localization. However, it is $4-5 \%$ in colorectal cancer and frequently localized on abdomen. Skin metastasis generally occurs in late terms with a poorer prognosis. ${ }^{2,3}$ Our patient had skin metas- tasis on forehead after approximately 7 months of multiple liver metastasis. The skin metastasis is generally expected to occur as multiple lesions, however she had it as an isolated lesion on forehead. So, it seems to occur as an unexpected pattern in terms of both presentation and localization. Miguel et al reported a case with subcutaneous nodular metastasis in rectum cancer. ${ }^{5}$ But, the skin metastasis in our patient was ulcerated and fragile (Figure 1). Saladzinskas et al reported a case with synchronous lip and lung metastasis in whom they had applied metastasectomy for both metastasis. ${ }^{6}$

Our patient seems to be more interesting. Because, other cases reported with skin involvement in the literature are generally accompanied by locoregional involvements like parotideal or mandibular involvements. ${ }^{7-10}$

In conclusion, skin lesions in cancer patients should be evaluated for both metastasis and second primary skin cancers, even in those with rare skin metastastatic pattern like colorectal cancer.

\section{REFERENCES}

1. http://globocan.iarc.2012.fr/Pages/fact_sheets_population.aspx (access date: June 09, 2015).

2. Krathen RA1, Orengo IF, Rosen T. Cutaneousmetastasis: a meta-analysis of data. South Med J 96: 164-167, 2003.

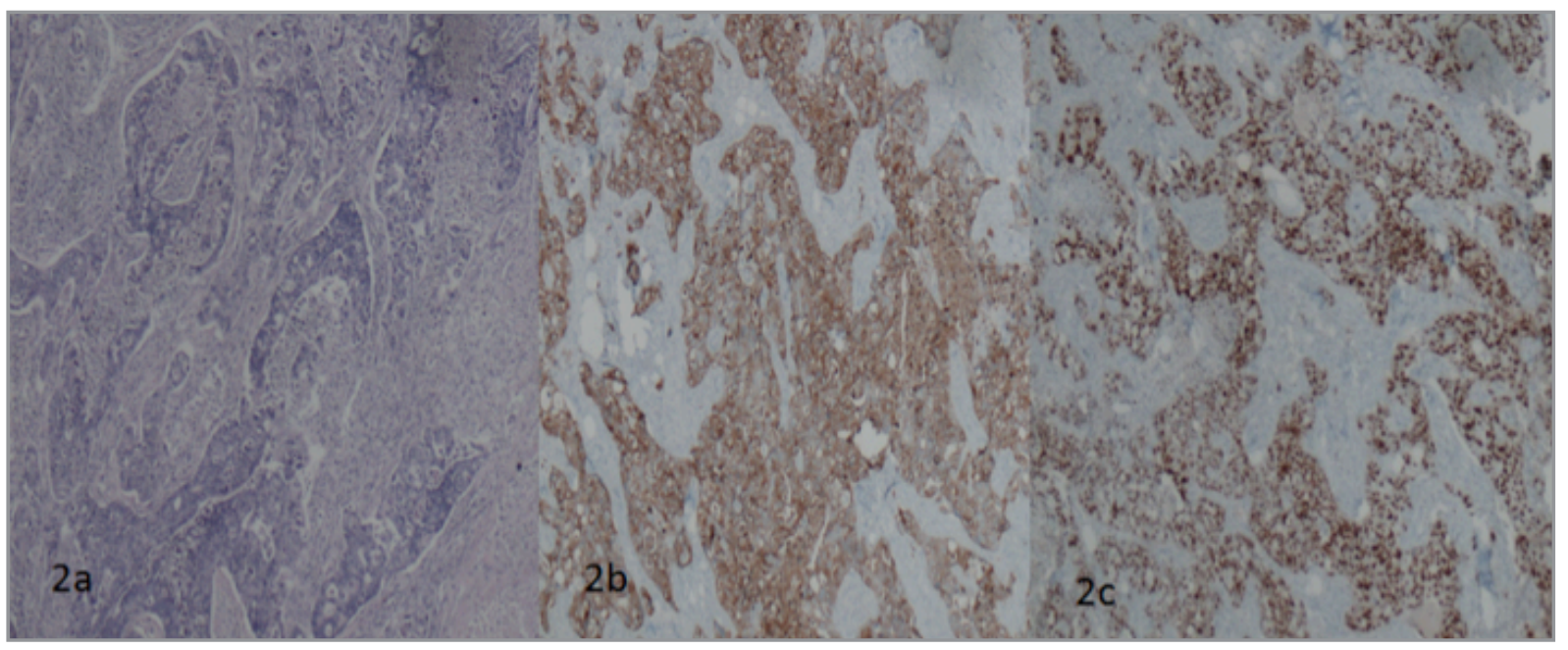

Figure 2: Histopathology revealed rectum cancer metastasis (a) Tumor cell islands with focal necrosis and cribriform pattern in the desmoplastic stroma (HE, x40) (b) Diffuse positive CK20 cytoplasmic staining in the tumor cells (CK20, x40) (c) Diffuse strongly nuclear CDX2 expression in the tumor cells (CDX2, x40) 
3. Lookingbill DP1, Spangler N, Sexton FM. Skin involvement as the presenting sign of internal carcinoma. A retrospectivestudy of 7316 cancer patients. J Am Acad Dermatol 22: 19-26, 1990.

4. X- Raju Kucheralapati. Biology of personalized cancer medicine. In cancer principles and practice of oncology. Devita VT,Lawrence TS, rosenberg SA(eds). 9.edition. Lippincott Williams and wilkins, a Wolters Kluwer Business 2011: 113-128.

5. deMiguel Valencia MJ, FraileGonzález M, Yagüe Hernando $A$, et al. Cutaneous metastases of rectal cancer. An SistSanit Navar 36: 557-561, 2013.

6. Saladzinskas Z, Tamelis A, Paskauskas S, et al. Facial skin metastasis of colorectal cancer: a case report. Cases J 15: 28, 2010.

7. Hashimi Y, Dholakia S. Facial cutaneous metastasis of colorectal adenocarcinoma. BMJ Case Rep 31: 2013. doi: 10.1136/bcr-2013-009875.

8. Nasti G1, Facchini G, Caraglia M, et al. Concomitant occurrence of facial cutaneous and parotid glandmetastases from rectal cancer after preoperative chemoradiotherapy. Onkologie 30: 324-326, 2007.

9. Warchol R1, Szymanski L, Seichter A. Rectal adenocarcinoma metastasis to the facial skin. Casereport Otolaryngol Pol 62: 96-99, 2008.

10. Eichinger J1, George B, Myhand R. Cutaneous metastatic rectal carcinoma masquerading as herpes zoster. South Med J 104: 233-235, 2011.

\section{Correspondence}

Dr. Doğan YAZILITAŞ

Ankara Numune Eğitim ve Araştırma Hastanesi

Tıbbi Onkoloji Bölümü

Altındağ, ANKARA / TURKEY

İs Tel: (+90.312) 5184611

e-mail: doganyazilitas@yahoo.com 